\title{
Kant e a influência da educação na política e na ideia de uma paz perpétua
}

João Paulo Martins ${ }^{1}$, Marcos Roberto de Faria ${ }^{2}$

\section{Resumo}

Este artigo visa refletir sobre a educação a partir do pensamento do filósofo alemão Immanuel Kant (1724-1804). O principal objetivo é apresentar o pensamento kantiano sobre a educação em sua relação com a ideia de paz perpétua. Ao realizar tal reflexão, notamos que a educação proposta pelo filósofo exerce papel importante na formação moral dos indivíduos e logo há uma incidência na formação social, contribuindo positivamente no processo da realização de uma ordem mundial cosmopolita e da consequente obtenção de uma paz perpétua.

\section{Palavras-chave}

Kant. Educação. Ética. Paz Perpétua.

1 Mestre em Educação pela Universidade Federal de Alfenas, Minas Gerais, Brasil. E-mail: joaoptc22@hotmail.com.

2 Doutor em Educação pela Pontifícia Universidade Católica de São Paulo, Brasil, com período de estágio sanduíche na Università Degli Studi di Udine, Itália; professor associado na Universidade Federal de Alfenas, Minas Gerais, Brasil. E-mail: marcosfaria07@yahoo.com.br. 


\title{
Kant and education influence on politics and on the idea of a perpetual peace
}

João Paulo Martins ${ }^{3}$, Marcos Roberto de Faria ${ }^{4}$

\begin{abstract}
This article aims to reflect on education from the thinking of the German philosopher Immanuel Kant (1724-1804). The main purpose of this article is to present Kant's thinking about education in its relation with the idea of perpetual peace. By doing so, we figure out the education proposed by Kant plays an important role on individuals' moral constitution and there is soon an impact on social formation, contributing positively on the realization process of a cosmopolitan world order and consequent achievement of a perpetual peace.
\end{abstract}

\section{Keywords}

Kant. Education. Ethic. Perpetual Peace.

3 Master in Education, Federal University of Alfenas, State of Minas Gerais, Brazil. E-mail: joaoptc22@hotmail.com.

${ }^{4} \mathrm{PhD}$ in Education, Pontifical Catholic University of São Paulo, State of São Paulo, Brazil, with a sandwich internship at Università Degli Studi di Udine, Italy; associate professor at the Federal University of Alfenas, State of Minas Gerais, Brazil. E-mail: marcosfaria07@yahoo.com.br. 


\section{INTRODUÇÃO}

Immanuel Kant, filósofo alemão, nasce em 22 de abril de 1724, na cidade de Königsberg, onde estuda, ensina e vive até sua morte, em 12 de fevereiro de 1804. Sua educação é vista como caminho que afasta o ser humano de suas inclinações instintivas e o direciona pelo caminho da liberdade, para o alcance de sua faculdade racional, elevando o ser humano ao seu melhor estado de humanidade. Na perspectiva kantiana, a educação instrui o sujeito, conduzindo-o para a moralização e para a busca de uma sociedade mais justa e pacífica, na qual a paz reine de forma soberana e perpétua, conquistando o mundo inteiro em uma dimensão de "sentimento cosmopolita" (KANT, 2002, p. 106).

A investigação aqui desenvolvida é de natureza teórica e estruturada segundo o rigor, a criticidade e a visão de conjunto, próprios das abordagens filosoficamente reflexivas e dialéticas. Para tanto, como referencial teórico principal desta investigação, apoiar-nos-emos na obra Sobre a Pedagogia (2002), em alemão Über Pädagogik, editada pelo ex-estudante Friedrich Theodor Rink, e publicada em 1803, um ano antes da morte de Kant. A análise dessa obra nos permite esclarecer as ideias do autor sobre a educação bem como nos possibilita a apreensão e a interpretação acerca do significado filosófico e antropológico das questões relativas à educação moral.

Kant (2002) apresenta, na obra supracitada, as três disposições naturais do ser humano, a saber, a disposição para a animalidade, na medida em que é um ser vivo propenso aos impulsos e inclinado aos instintos; a disposição para a humanidade, enquanto ser vivo dotado de racionalidade; e a disposição para o caráter, enquanto ser racional e capaz de viver a moralidade.

Feitas essas considerações, ressaltamos a importância dos escritos kantianos serem interpretados de maneira sistemática, pois

\footnotetext{
em qualquer obra, sobretudo quando se desenvolve em discurso livre, se podem respigar aparentes contradições, confrontando entre si passos isolados, arrancados do contexto e que, aos olhos dos que se fiam nos juízos alheios, lançam sobre ela, porventura, uma luz desfavorável; essas contradições são, contudo, bem fáceis de resolver para quem se apoderou da ideia global da obra. (KANT, 2001, p. 61).
}

As obras kantianas, ainda que escritas e publicadas de forma singular e com especificidades próprias, possuem valor sistemático nas suas interpretações. Elas se completam quando lidas, 
respeitando o sentido de totalidade presente no pensamento do autor. Em Kant, é essa visão global que possibilita-nos refletir uma educação em vista da paz perpétua.

\section{Educação e a ideia de uma paz perpétua}

A educação proposta por Kant exerce papel importante na formação moral dos indivíduos e, logo, há uma incidência na formação social, pois esse aprendizado contribui positivamente no processo da realização de uma ordem mundial cosmopolita e da consequente obtenção de uma paz perpétua.

Nas Lições de Ética ${ }^{5}$, em sua parte final, o filósofo afirma que a felicidade é alcançada mediante a liberdade humana. Só seremos dignos dessa felicidade por meio da perfeição moral. Tal perfeição não é uma dádiva divina, mas uma conquista que a espécie humana é livre para buscar.

A destinação final do gênero humano é a maior perfeição moral na medida em que é realizada através da liberdade do homem por meio do qual ele é, nesse caso, capaz da maior perfeição. Deus já poderia ter feito os homens completamente perfeitos e ter compartilhado com todos a felicidade. Mas, nesse caso, ela não emergiria a partir do principium interno do mundo. Este princípio interno é, no entanto, a liberdade. A destinação do homem é, portanto, obter a maior perfeição por meio de sua liberdade. (KANT, 2018, p. 505).

A liberdade é esse princípio universal que permite ao ser humano a moralidade e esta nos leva à perfeição, na medida em que todos nós buscamos vivê-la. Assim,

o fim universal da humanidade é a suprema perfeição moral: se todos pudessem agora se comportar de modo que sua conduta concordasse com este fim universal, então, a perfeição suprema seria, dessa forma, alcançada. Por isso todo indivíduo deve se esforçar para estabelecer sua conduta de acordo com este fim por meio do qual ele contribui para isso de tal maneira que, se agora todos fazem o mesmo, a perfeição moral é alcançada. (KANT, 2018, p. 506).

Notemos que tal suprema perfeição moral deve ser buscada por cada indivíduo, porém ela não termina nele mesmo com objetivos particulares e subjetivos. Ela objetiva a perfeição universal, válida para toda a humanidade. Diante disso, o próprio filósofo se indaga:

\footnotetext{
${ }^{5}$ Lições de Ética (Vorlesungüber Ethik) é um texto de Kant, trazido à luz em 1924, por Paul Menzer. O texto passara por uma reedição feita por Gerhard Lehmann em 1974. Sobre os cuidados de Werner Stark, o texto fora publicado como obra em 2004, sendo recentemente (2018) traduzida do alemão para o português por Bruno Cunha, professor da Universidade Federal de São João del Rei, e por Charles Feldhaus, professor da Universidade Estadual de Londrina.
} 
Ora, mas como devemos buscar essa perfeição e a partir de onde podemos esperá-la? De nenhum outro lugar além da educação. Esta deve estar de acordo com todos os fins da natureza, da sociedade civil e da vida doméstica. Mas nossa educação em casa e nas escolas é bastante defeituosa, não apenas em relação à disciplina, à doutrina e à cultura do talento, mas também em vista da formação do caráter de acordo com princípios morais. (KANT, 2018, p. 507).

É nesse sentido que Kant (2002) entende a educação como uma arte que precisa ser sempre aprimorada, isto é, a educação é algo que está em construção e não algo já dado, pronto. Ela deve ser pensada a partir de um ideal de perfeição, de um estado no qual ela ainda não se encontra, mas que almeja, pois um projeto educacional deve pautar-se sempre em um estado de melhoramento humano, de modo a corrigir seus defeitos, assegurando que estes não sejam levados a diante. Entretanto, ainda assim, haverá dificuldade de se estabelecer uma educação que rompa com os defeitos e eduque os sujeitos em vista da formação do caráter moral. O ser humano inclina-se muito mais para aquilo sensível do que para as coisas vindas do intelecto. Para ele chegar à retidão moral, é preciso usar os princípios do entendimento e afastar-se dos impulsos da sensibilidade, como constata Cunha (2016):

Embora o entendimento seja capaz de identificar, por meio da aprovação do juízo, o que é a bondade e a retidão moral [rectitudo moralis], uma vez que a perfeição moral é um produto do intelecto, Kant admite que um motivo proporcionado pelo entendimento não possui uma força impulsora tão forte quanto à da sensibilidade. Esta característica justifica o motivo pelo qual, devido a uma fraqueza essencial, a natureza humana carece de bondade e retidão moral. Todavia, o fato de admitir esse tipo de fraqueza não implica, necessariamente, que o homem deva perder sua confiança em realizar ações moralmente boas e puras. (CUNHA, 2016, p. 210).

Dado que o indivíduo inclina-se mais para a sensibilidade que para o entendimento, dificultando a retidão moral, é necessário um esforço pedagógico, de modo a cultivar os princípios da razão para atenuar esse dado, ou seja, é preciso que o sujeito seja estimulado a fazer usos dos conceitos da própria razão (KANT, 2002, p. 93). Nesse sentido, a educação moral traduz-se como estratégia humana para fazer bom uso da razão, considerada faculdade natural, exatamente por não se assemelhar ao instinto. No entanto, para Kant (2007), tornar um indivíduo moralmente melhor só é possível se ele próprio cultivar a razão de acordo com seu fim, isto é, praticar o dever a partir do crivo da lei moral.

Esta contribuição para o melhoramento da conduta é algo que devemos esperar apenas da educação moral. Na perspectiva kantiana, uma educação em vista da retidão moral é aquela que torna o indivíduo apto racionalmente, livre e consciente para que ele possa, a partir do uso de suas forças, guiar-se pela razão sem se pender às inclinações sensíveis, pois, assim, o 
progresso humano se beneficiará da formação de um caráter bom o suficiente para distinguir máximas boas das más. Por isso, tudo que vem a nós deve passar pelo tribunal da razão, isso faz com que nos tornemos maiores. A razão é uma espécie de juiz capaz de julgar tudo que nos chega à mente. E, nesse sentido, pensar por si mesmo significa procurar a verdade em nós mesmos e esta deve ser encontrada na nossa faculdade racional.

Por todo lado, existem tutores que se beneficiam do fato de não fazermos uso da nossa razão. Eles aproveitam da nossa condição de menoridade, dizendo que não somos capazes de pensar sozinhos, querem-nos obedecendo sem questionar. Com medo disso, deixamo-nos ser guiados por esses tutores que limitam nossa liberdade. Em todo lugar, existe pessoa querendo monopolizar o conhecimento, a verdade. Tornar uma ideia pública é pô-la à prova, é pô-la na situação de crítica. É preciso passar tudo pelo crivo da razão.

Do mesmo modo que a razão humana ajuda-nos construir o conhecimento, ela também pode nos ajudar na construção de uma civilização mais íntegra e ética. A busca pela moralidade é uma tentativa metafisica de compreender a legislação natural, é a busca pelo fenômeno que está por trás do fato acontecido. O princípio supremo da moralidade é o da autonomia.

Mas de que modo podemos educar para a autonomia sem usarmos da heteronomia? Assim diz Kant:

Um dos maiores problemas da educação é o de poder conciliar a submissão ao constrangimento das leis com o exercício da liberdade. Na verdade, o constrangimento é necessário! É preciso habituar o educando a suportar que a sua liberdade seja submetida ao constrangimento de outrem e que, ao mesmo tempo, dirija corretamente a sua liberdade. Sem esta condição, não haverá nele senão algo mecânico; e o homem, terminada a sua educação, não saberá usar sua liberdade. É necessário que ele sinta logo a inevitável resistência da sociedade, para que aprenda a conhecer o quanto é difícil bastar-se a si mesmo, tolerar as privações e adquirir o que é necessário para tornar-se independente. (KANT, 2002, p. 32-33).

A filosofia kantiana aponta para uma proposta que é, no plano individual, a busca pela virtude e, no plano político, a busca pela paz perpétua. Porém, é preciso ressaltar que o plano da educação não diz respeito apenas à pessoa, mas também à sociedade. No plano educacional da pessoa humana, o importante é transformar todos os sujeitos humanos em pessoas disciplinadas, que consigam viver colocando de lado a parte instintiva animal e busquem viver as potencialidades das suas particularidades. É necessário que, no plano social, busquem ser cultas e com espírito de paz, pois a educação é para a vida prática, tendo a paz perpétua como bem comum. 
No intuito de possibilitar uma educação que vise à paz, faz-se fundamental o estabelecimento efetivo de uma pedagogia no seio da sociedade. A escola deve assumir uma função especial ante tais práticas pedagógicas, porquanto lhe cabe ser um espaço de aprendizagem, de reflexão e de convívio promotor da paz.

Para se chegar à paz perpétua, entendida como o fim de todas as hostilidades entre as nações, são precisos mais que tratados de paz, é necessário um acordo, o qual se dê sem ressalvas que possam deflagrar guerras futuras (KANT, 2006, p. 57).

A verdadeira política não pode dar um passo sem haver antes rendido respeito à moral e, ainda que a política seja por si mesma uma arte difícil, não é, sem dúvida, a união da política com a moral, pois esta corta o nó que a política não pode solucionar quando surgem discrepâncias entre ambas. $\mathrm{O}$ Direito dos homens deve manter-se como coisa sagrada, por maiores que sejam os sacrifícios do poder dominante. Neste assunto não se pode partir em dois e inventar um intermediário (entre direito e utilidade) de um direito condicionado pela prática. Toda política deve ajoelhar-se ante o Direito, apesar de caber esperar que se chegue a um nível, ainda que lentamente, em que a política brilhará com firmeza. (KANT, 2006, p. 111).

A célebre máxima de que "a paz é fruto da justiça" coloca-nos diante de um conceito de direito que corresponda verdadeiramente a esse propósito de justiça. Só a partir da ideia de um direito único, isto é, que seja o mesmo para toda a humanidade, que se tornará possível desenvolver a paz total. Por paz compreendemos também a ausência de guerra entre as nações, a extinção da violência e dos conflitos entre pessoas, tendo como resultado a obtenção do sossego, da serenidade, da justiça e, consequentemente, da coesão social.

$\mathrm{Na}$ tentativa de promover a justiça no mundo, deparamo-nos com a necessidade de uma educação para a paz. Na perspectiva kantiana, é com a educação que temos a possibilidade de organizar a ideia de humanidade e, dessa maneira, de uma cultura de paz. A questão da paz é uma espécie de finalidade última entre os acordos das nações.

Entretanto, para se chegar à paz universal, é preciso estabelecer a justiça mundial, pois é a partir de um compromisso entre os seres humanos e os estados que poderá existir uma educação voltada a universalizar a justiça e atingir a paz. Uma sociedade politicamente justa tornará possível atingir a paz perpétua.

A Providência quis que o homem extraísse de si mesmo o bem e, por assim dizer, desse modo lhe fala: "Entra no mundo. Coloquei em ti toda espécie de disposições para o bem. Agora compete somente a ti desenvolvê-las e a tua felicidade ou a tua infelicidade depende de ti”. (KANT, 2002, p. 19). 
A partir da obra Sobre a Pedagogia, vimos que o ser humano é a única criatura que necessita ser educada desde cedo, ele possui e depende de sua razão para melhor controlar a sua vida. Assim, a educação torna-se o elemento que irá esclarecer o ser humano em vista da paz perpétua, permitindo-lhe ajuizar a distinção entre o bem e o mal.

Quando Kant (2002) atribui à educação a incumbência de tirar a selvageria humana, ele está mostrando a necessidade de o ser humano afastar-se das inclinações dos instintos e eliminar os maus hábitos. Como vimos, a educação disciplinar exerce papel importante na superação da animalidade e ajuda o indivíduo encontrar-se com sua humanidade (KANT, 2002). Nesse sentido, cada pessoa deve colocar-se a serviço da inteira humanidade, sempre vendo a outra como fim em si mesmo, pois perceber-se como membro da humanidade é perceber que todos as outros são dignos de reconhecimento como fins em si.

O homem precisa da formação escolástica, ou da instrução, para estar habilitado a conseguir todos os seus fins. Essa formação lhe dá um valor em relação a si mesmo, como indivíduo. A formação da prudência, porém, o prepara para tornar-se um cidadão, uma vez que lhe confere um valor público. Desse modo ele aprende tanto a tirar partido da sociedade civil para os seus fins como a conformar-se à sociedade. Finalmente, a formação moral lhe dá valor que diz respeito à inteira espécie humana. (KANT, 2002, p. 35)

Ser um fim em si mesmo é reconhecer a dignidade humana, dignidade essa que coloca os seres humanos em posição privilegiada ante as demais criaturas, já que na condição de sermos possuidores de uma razão, somos capazes de não ficar sob as inclinações de nossos instintos e das determinações de nossa natureza. Essa é a marca da nossa humanidade em si mesma. $\mathrm{O}$ dever para conosco mesmos nos chama ao dever em relação aos outros. Assim, percebermonos como humanidade significa ver que somos iguais, ou seja, é tanto notar a não diferença entre os seres humanos quanto compreender a razão como condição legisladora universal, que por meio da educação pode conduzir a humanidade ao estado de paz.

Ao trabalhar a ideia kantiana de que a educação é uma arte que precisa ser constantemente aperfeiçoada ao longo das gerações, reconhecemos que educar para a paz deve ser algo sempre pensado sob o viés de um longo processo, durante o qual o educando vai aos poucos buscando a perfeição, reconhecendo e identificando as causas naturais dos conflitos entre os seres humanos, suas diferenças individuais. Os processos educativos dão aos educandos a 
possibilidade de dirimir os conflitos por meio do diálogo e do entendimento, a fim de criar um clima de paz entre as pessoas e também entre os Estados ${ }^{6}$.

Uma educação que visa à paz deve começar no ceio doméstico, porquanto é na família que a criança inicia sua vida em comunidade. Se a escola é importante para socializar as crianças, o seio familiar é fundamental para elas aprenderem a reconhecer tanto o sentimento do amor quanto o valor da disciplina.

Mas o homem é tão naturalmente inclinado à liberdade que, depois que se acostuma a ela por longo tempo, a ela tudo sacrifica. Ora, esse é o motivo preciso, pelo qual é conveniente recorrer cedo à disciplina; pois de outro modo, seria muito difícil mudar depois de homem. Ele seguiria, então, todos os seus caprichos. (KANT, 2002, p. 13).

Percebemos assim que a família e a escola são os locais privilegiados para desenvolver a formação do ser humano pacífico: a família, disciplinando a criança desde cedo em vista do bom uso da liberdade; a escola, por sua vez, trabalhando o valor da solidariedade, do respeito mútuo e da tolerância para com as diferenças. No entanto, ao se sentir membro da humanidade, o sujeito valorizará esses princípios fundamentais da solidariedade, do respeito e da tolerância. Esse trabalho, da família e da escola, é fundamental para a obtenção de uma paz duradoura.

Kant (2002, p. 23) entende que "no homem não há germes, senão para o bem", os quais o conduzem rumo à moralidade, atingindo a autonomia em uma sociedade mais justa.

Os pais cuidam da casa, os príncipes, do Estado. Uns e outros deixam de se propor como fim último o bem geral e a perfeição a que está destinada a humanidade e para a qual esta tem as disposições. O estabelecimento de um projeto educativo deve ser executado de modo cosmopolita. [...] Uma boa educação é justamente a fonte de todo bem neste mundo. Os germes que são depositados no homem devem ser desenvolvidos sempre mais. (KANT, 2002, p. 23).

Se a educação é a fonte de todo bem no mundo, isso faz com que os educadores tornam-se ainda mais responsáveis por aquilo que ensinam aos seus alunos, exigindo daqueles uma postura de permanente aperfeiçoamento de suas práticas pedagógicas.

\footnotetext{
${ }^{6}$ Para Kant, o Estado "é uma sociedade de homens sobre a que ninguém, mais que ela mesma, tem que mandar e dispor”. O Estado não pode ser entendido como uma coisa da qual as pessoas se dispõem ao bel prazer. Ele não é um objeto. O Estado é o sujeito do direito das gentes. Não há proprietário do Estado a não ser o próprio povo que a ele pertence (KANT, 2006, p. 58).
} 
Tudo o que se opõe à moral deve ser excluído dos propósitos. Num homem mau o caráter é muito ruim. Aqui se trata de obstinação, ainda que se aprecie sempre vê-lo seguir suas decisões e permanecer constante; se bem que mais valeria vê-lo constante no bem. (KANT, 2002, p. 88).

Nesse sentido, os educadores não devem forçar seus educandos a obedecerem cegamente, mas o processo educativo deve seguir na direção de formar sujeitos pacíficos e não passivos, pois a obediência deve estar atrelada ao conhecimento, de modo que o ser humano não haja inclinado pelo impulso ou mesmo obedecendo tão somente a uma autoridade sem saber as razões e as consequências de tais atitudes.

Antes de mais nada, a obediência é elemento essencial do caráter de uma criança e, sobretudo, de um escolar. Ela tem duplo aspecto: o primeiro é a obediência à vontade absoluta de um governante, ou também a obediência à vontade de um governante reconhecida como razoável e boa. A obediência pode proceder da autoridade - e, então é absoluta - ou da confiança - e, nesse caso, é de outro tipo. Essa última, a voluntária, é importantíssima; mas a primeira é absolutamente necessária, porque prepara a criança para o respeito às leis que deverá seguir corretamente como cidadão, ainda que não lhe agradem. (KANT, 2002, p. 77).

Todos devem respeito e obediência às leis, pois, considerando que elas são elaboradas de acordo com os princípios racionais, somos todos súditos e legisladores ao mesmo tempo. Assim, percebemos que "um homem que toma uma decisão e não cumpre, não pode ter confiança em si mesmo" (KANT, 2002, p. 87). Agindo assim, ele enfraquece seu propósito, descumpre-se o seu dever e distancia-se da autonomia. O sujeito, ao distanciar-se da sua autonomia, contraria suas próprias atitudes, distanciando-se de sua maioridade e, consequentemente, da moralidade. Uma ação tenderá, portanto, a ter mais sucesso e ser boa, se estiver pautada sobre a máxima do dever. Ademais, segundo Kant (2002, p. 76),

O caráter consiste no hábito de agir segundo certas máximas. Estas são, em princípio, as da escola e mais tarde, as da humanidade. Em princípio, as crianças obedecem às leis. Até as máximas são leis, mas subjetivas; elas derivam da própria inteligência do homem.

A formação do caráter é um ato de liberdade em prol da humanidade. Ao orientar o educando para a humanidade e para o trato com os outros, o ato pedagógico deve garantir tanto o desenvolvimento do indivíduo, assegurando a subjetividade humana, quanto deve estar voltado para aqueles que o cercam. Desse modo, o desenvolvimento humano, entendido por educação prática ou moral, consiste em viver como um ser livre, tendo em vista a sua subjetividade, mas não apenas bastando-se a si mesmo, mas antes se constituindo como membro da sociedade. Essa educação pode levar a humanidade a um estágio de paz perpétua. 
O convívio em sociedade e a interação com o diverso desperta-nos o sentimento da verdadeira necessidade de colocarmo-nos no lugar do outro. Sem essa sociabilidade, tendemos a satisfazer-nos enquanto individualidades e a olhar apenas para os nossos próprios interesses. A nossa interação com o outro faz as diferenças aparecem. Essa é a possibilidade de aperfeiçoarmo-nos enquanto seres humanos. Nesse contexto, a escola torna-se um laboratório para o processo de desenvolvimento rumo à paz, a medida que proporciona espaços de convívio e interação.

O estado de paz permite uma vida de alegria e de tranquilidade. Para Kant (2002, p. 106), "a alegria do coração deriva da consciência tranquila, da igualdade de humor. Mas é a partir da vivência da moralidade que se pode ter a consciência tranquila", pois "devo considerar uma ação como valiosa, não porque se adapta à minha inclinação, mas porque através dela eu cumpro meu dever". No cumprimento do dever, pode-se almejar uma sociedade na qual haja uma melhor coesão social e, consequentemente, a paz entre os seres humanos.

É necessário acostumar o jovem a se estimar absolutamente e não relativamente aos outros. A estima dos outros, em tudo aquilo que não constitui de fato o valor do ser humano, é vaidade. É preciso, além disso, ensinar ao adolescente e a ter todo cuidado, não tanto aparecer, mas em ser. (KANT, 2002, p. 105).

A verdadeira essência humana consiste em ser um sujeito autônomo, o qual faz o melhor uso público e privado de sua razão, sempre pensando no bem universal. Assim, a paz exige que o sujeito saiba quando manifestar suas convicções pessoais - "uso público da razão" -, e exige saber quando deve privar o público em nome do próprio interesse público - "uso privado da razão" (KANT, 1985, p. 104).

Na perspectiva kantiana, educação instrui o sujeito, conduzindo-o para a moralização e para a busca de uma sociedade mais justa e pacífica, na qual a paz reine de forma soberana e perpétua, conquistando o mundo inteiro em uma dimensão de "sentimento cosmopolita" (KANT, 2002, p. 106).

Para que o estado de paz seja alcançado em nosso meio, é preciso que ele seja um desejo de todos nós e seja buscado por vários segmentos institucionais da sociedade, indo desde a instrução doméstica à educação escolar, passando pelas formas de governo (Estado), de modo que o engajamento atinja o bem de toda a nação. Desse modo, a política torna-se o palco para estabelecer princípios práticos, isto é, ela deve, por meio da legalidade, instituir leis do direito 
para conduzir a espécie humana rumo ao reino da moralidade e da paz. Tal condução colocarnos-á próximos à paz perpétua, universalmente dimensionada, pois

Avançou-se tanto no estabelecimento de uma comunidade (mais ou menos estreita) entre os povos terrestres que, como resultado, a violação do direito em um ponto da terra repercute em todos os demais, a ideia de um Direito Cosmopolita não é uma representação fantástica nem extravagante, mas completa o código não escrito do Direito Político e do Direito de Gentes em um Direito Público da Humanidade, sendo um complemento da paz perpétua, ao constituir-se em condição para uma contínua aproximação a ela. (KANT, 2006, p. 82).

Se, por um lado, no plano individual a educação kantiana tem por objetivo final constituir o sujeito moral, então, por outro, no plano político tal educação terá por finalidade atingir a paz perpétua. Como vimos, a princípio, no estado de natureza, o ser humano precisa ser educado para conter sua selvageria e retirar sua animalidade, para chegar ao estado moral e, conseguinte, ao seu estado de humanidade. Depois, em termos políticos, o Estado também precisa ser fundado a partir da ideia de um "direito cosmopolita", por meio do qual as leis tenham dimensão que assegurem direitos e deveres às pessoas de todo o mundo, às gentes de toda humanidade.

Só assim, por meio de um direito de esfera cosmopolita, se pode assegurar o processo de desenvolvimento interno dos Estados, pois o indivíduo precisa de uma segurança interna, que será dada pelas leis de cada Estado, a fim de permanecer progredindo em direção a sua finalidade, qual seja, a paz perpétua.

Percebemos ser importante um direito que sirva a todas as gentes e, ao mesmo tempo, deva ser posto de forma interna em cada Estado, pois, segundo Kant (2006, p. 90),

as leis perdem a sua eficácia ao aumentar os territórios a serem governados e porque um despotismo sem alma cai, ao final, em anarquia, depois de haver aniquilado os gérmens do bem. Contudo, a vontade de todo Estado (ou da sua autoridade suprema) é chegar à situação de paz duradoura dominando todo o mundo, se for possível.

Portanto, uma educação que preze pelos direitos cosmopolitas deve se atentar para fazê-los chegar aos conhecimentos dos seus educandos. São nos diversos segmentos da sociedade (como a família, a escola, as instituições) que esses germes do bem podem ser cultivados mais de perto, de forma a assegurar esses direitos ${ }^{7}$ :

\footnotetext{
${ }^{7}$ No entendimento kantiano, “O Direito dos homens deve manter-se como coisa sagrada, por maiores que sejam os sacrifícios do poder dominante. Neste assunto não se pode partir em dois e inventar um intermediário (entre direito e utilidade) de um direito condicionado pela prática. Toda política deve ajoelhar-se ante o Direito, apesar
} 
A condição da possibilidade de um Direito de Gentes como tal é que exige previamente um estado jurídico. Sem este não se dá o Direito Público e todo o direito que se possa pensar fora daquele (em estado de natureza) é mero Direito Privado. Antes vimos que uma federação de Estados que tenha como finalidade evitar a guerra é o único estado jurídico compatível com a sua liberdade. (KANT, 2006, p. 114).

Depreende-se do acima citado que ao Estado, onde as leis sejam todas oriundas dos cidadãos, cabe ao governante impor a lei, não a sua lei, mas sim a lei que é fundada a partir dos princípios racionais, motivo pelo qual ela se torna pertencentes a todos os seres racionais. $\mathrm{O}$ desenvolvimento da razão humana garante a formação desses princípios, uma vez ser ela esclarecedora. Por isso, Kant (1985) afirma a necessidade do esclarecimento.

Nesse sentido, devemos voltar ao conceito kantiano de uso "público da razão". Nos escritos sobre $O$ que o Esclarecimento? encontramos a ideia de que fazer uso da razão é uma forma de dar publicidade ao conhecimento. Não diferentemente acontece com a educação escolar: ao ensinar algo, está se publicando um entendimento que até então estava na "razão privada". O processo educativo é a manifestação dessas duas consciências: privada e pública.

Retomar o conceito de "razão pública" ajuda-nos entender o critério de publicidade defendido por Kant em À paz perpétua, pois nessa obra o filósofo de Königsberg busca estabelecer a "publicidade" como elemento que possibilita uma sociedade justa, em vista de um Estado de paz. Se o esclarecimento necessita da publicidade, de maneira semelhante deve acontecer com a paz. Assim, diz Kant (2006, p. 109):

Se no Direito Público, prescindo, como costumam conceber os juristas, de toda matéria (das diferentes relações empiricamente dadas nos homens no Estado ou entre Estados), ainda me resta a forma da publicidade, cuja possibilidade está contida em toda a pretensão jurídica, já que sem ela não haveria justiça (que somente pode ser pensada como publicamente manifesta) nem haveria tampouco Direito, que somente se outorga desde a Justiça.

Percebemos, então, que a publicidade é a maneira pela qual podemos exigir algo, isto é, fazermos não somente conhecer as leis mas também as fazer valer:

de caber esperar que se chegue a um nível, ainda que lentamente, em que a política brilhará com firmeza." (KANT, 2006, p. 107). Em outras palavras, o direito e a moral são imprescindíveis para que a política não se torne abusiva, despótica e corruptível.

${ }^{8}$ Sobre o que é o uso público da razão, reponde Kant: "o uso público de sua razão deve sempre ser livre e só ele pode realizar o esclarecimento entre os homens. O uso privado da razão pode porém muitas vezes ser muito estreitamente limitado, sem contudo por isso impedir notavelmente o progresso do esclarecimento. Mas por uso público da própria razão entendo aquele que qualquer um, enquanto letrado (Gelehrter), dela faz perante o grande público do mundo letrado. Chamo uso privado àquele que alguém pode fazer da sua razão num certo cargo público ou função a ele confiado" (KANT, 1985, p. 104). 
Toda pretensão jurídica deve possuir esta possibilidade de ser publicada e a publicidade pode, por isso, proporcionar um critério a priori da razão, de fácil utilização, para conhecer imediatamente, como por um experimento da razão pura, a falsidade da pretensão (antijuridicidade) no caso de que não se dê a publicidade, já que se torna muito fácil reconhecer se se dá em um caso concreto, ou seja, se a publicidade se pode harmonizar ou não com os princípios do agente. (KANT, 2006, p. 109).

A publicidade é um dos conceitos básicos do pensamento político de Kant. Ela apresenta-se como uma diretriz cuja finalidade é a ação do sujeito, de tal modo que seja universal (direito de todos) querer essa máxima:

Se unicamente por meio da publicidade é como podem alcançar o seu fim, o é porque se adequam ao fim geral do público (a felicidade), e a tarefa própria da política é estar de acordo com este fim (fazer com que o público esteja contente com a sua situação). Se somente mediante a publicidade se pode conseguir este fim, ou seja, mediante a eliminação de toda desconfiança a respeito das máximas, estas têm que estar também em concordância com o Direito Público, pois somente no Direito é possível a união dos fins de todos. (KANT, 2006, p. 115-116).

Portanto, o direito é o melhor caminho para o pregresso universal dos povos e a forma de dar efetividade a tal direito pode ser encontrada na publicidade. Indo na mesma esteira da ideia anterior, em $O$ Conflitos das Faculdades, Kant alerta: “a interdição da publicidade impede o progresso de um povo para o melhor, mesmo no que concerne à menor das suas exigências, a saber, o seu simples direito natural” (KANT, 1983, p. 107).

Trata-se de organizar uma sociedade conforme sua representação, segundo leis naturais de liberdade, afastando-se das hostilidades e das guerras:

A ideia de uma constituição em consonância com o direito natural dos homens, a saber, que os que obedecem à lei devem ao mesmo tempo, na sua união, ser legisladores, está subjacente a todas as formas políticas, e o Estado que, concebido em conformidade com ele, graças a puros conceitos racionais, se chama um ideal platónico (res publica noumenon), não é uma quimera vazia, mas a norma eterna para toda a constituição civil em geral, e afasta toda a guerra. (KANT, 1983, p. 108).

Podemos dizer que não é absurdo, a partir do pensamento kantiano, buscar por um ideal de paz perpétua, ao contrário, é algo racional e viável, pois pensar um direito universal (de toda a gente), fundamentado na justiça, possui em si uma igualdade fundamental. Tanto é possível que essa justiça e igualdade estão garantidas atualmente pela Declaração Universal dos Direitos Humanos. Ela se fundamenta na dignidade humana. É nesse sentido que podemos dizer que a ideia kantiana torna-se possível e praticável. Ademais, em toda sociedade tem-se a necessidade de uma regulamentação garantidora da justiça. Torna-se cada vez mais urgente a 
necessidade de se educar para a cultura da paz. Acreditamos também que a mudança social depende de uma mudança de consciência e tal mudança de consciência acontece por meio do processo educativo.

Assim, na perspectiva kantiana, uma educação que contemple a disciplina é essencial para conter os ímpetos humanos e para lapidar a parte animal presente em cada indivíduo. Entendemos também que a educação instrutiva é responsável por preparar o ser humano para exercer sua liberdade em consonância com a razão, de modo que ele possa formar-se um ser moral, apropriar-se da cultura e, consequentemente, tornar-se um bom cidadão em vista da paz perpétua.

\section{CONSIDERAÇÕES FINAIS}

Em Kant, é na educação que se encontra a principal reivindicação para tirar a selvageria do homem e restringir seus impulsos. É na educação que o ser humano aprende os deveres para consigo mesmo e para com os outros. A pedagogia cumpre função fundamental, já que ela deve proporcionar os meios pelos quais a educação realiza-se cumprindo seu papel junto ao sujeito que, por sua vez, busca sair da menoridade e consolidar-se enquanto ser humano, alcançando sua maioridade, o seu melhor, isto é, tornando-se um sujeito autônomo, permitindo que o progresso moral ocorra como constituinte da humanidade do ser humano.

Assim, percebemos a meta da educação de levar o ser humano a realizar a sua destinação final, que, em sentido ético, é a realização de sua felicidade a partir da virtude e, em sentido político, é a consumação da paz perpétua.

\section{REFERÊNCIAS}

CUNHA, B. L. A gênese da ética de Kant: o desenvolvimento moral pré-crítico em sua relação com a teodiceia. 2016. 280 f. Tese (Doutorado em Filosofia) - Programa de pós graduação em filosofia, Universidade Federal de Minas Gerais, Belo Horizonte, 2016.

KANT, I. Crítica da Razão Pura. Tradução de Valério Rohden e de Udo Baldur Moosburguer. São Paulo: Nova Cultura; 2001. 
KANT, I. Fundamentação da metafísica dos costumes. Tradução de Paulo Quintela. Lisboa: Edições 70, 2007.

KANT, I. Ideia de uma história universal de um ponto de vista cosmopolita. Tradução de Artur Morão. São Paulo: Lusosofia Press, 2013.

KANT, I. Lições de ética. Tradução de Bruno Leonardo Cunha e Charles Feldhaus. São Paulo: Unesp, 2018.

KANT, I. O conflito das faculdades. Tradução de Artur Morão. Lisboa: Edições 70, 1983.

KANT, I. Para a paz perpétua. Tradução de Bárbara Kristensen. Galiza: Igesip, 2006.

KANT, I. Que significa orientar-se no pensamento? Resposta à pergunta: o que é esclarecimento? In: KANT, I. Textos seletos. Tradução de Floriano de Sousa Fernandes. Petrópolis: Vozes, 1985. p. 70-116.

KANT, I. Sobre a pedagogia. 3. ed. Tradução de Francisco Cock Fontanella. Piracicaba: Editora Unimep, 2002.

Submetido em 25 de fevereiro de 2019.

Aprovado em 20 de abril de 2019. 